\title{
Quality measures for lower gastrointestinal endoscopy: a review of recent consensus statements and guidelines
}

\author{
Umesh Jayarajah, Nilesh Fernandopulle \\ Department of Surgery, Faculty of Medicine, University of Colombo, Sri Lanka
}

Keywords: Quality; lower gastrointestinal endoscopy; colonoscopy

\begin{abstract}
Colonoscopy is utilised in the diagnosis and treatment of disorders of the lower gastrointestinal tract. Complete visualization of the large intestinal mucosa and also the terminal ileum should be done safely and in a well-tolerable manner. Colonoscopy plays a major role in screening for colorectal cancer and is useful in the early detection and prevention. Prevention of colorectal cancer requires prompt detection of potentially precancerous lesions and resection. In recent decades, considerable variation in performing colonoscopies and outcomes have been reported and therefore, the necessity for standardization of the procedure with quality measures was recognized. Quality/ performance measures are defined as indicators that aid in quantifying health-care processes and help to achieve high quality healthcare. Several quality indicators have been proposed in relation to pre-procedure preparation, intra-procedure and post-procedure events. Some of these quality measures include adenoma detection rate, caecal intubation rate, withdrawal times and quality of bowel preparation. Endoscopists should not only ensure adequate quality in relation to the above parameters but should also have high compliance rates with recommended guidelines on indications, evidence based screening and surveillance intervals. These will ensure better colonoscopy yields while maintaining high standards of patient safety and will translate into better patient outcomes.
\end{abstract}

Guidelines proposed by the American Society of Gastrointestinal endoscopy/American College of Gastroenterology and European Society of Gastrointestinal Endoscopy/United European Gastroenterology and recent evidence were analysed and the summary of the recommendations have been discussed in this review. Although these guidelines are not based on evidence from the Asian populations, it may still be useful to adopt these key quality measures for colonoscopy in

Correspondence: Nilesh Fernandopulle

E-mail: anrfernandopulle@yahoo.com

Received: 05-09-2019 Accepted: 09-12-2019

(iD) https://orcid.org/0000-0002-2169-8394

DOI: http://doi.org/10.4038/sljs.v37i4.8657
Asia. This will be helpful in the evaluation of daily practice at the endoscopy unit. However, guidelines targeting the regional population should be formulated in the future.

\section{Introduction}

Variations in the endoscopists' performance and several nationwide initiatives of colorectal cancer (CRC) screening programs resulted in the necessity for standardization of lower gastrointestinal endoscopy (1). During the recent decades, many potential quality control measures have been described and several scientific bodies have formulated guidelines and recommendations on quality measures for colonoscopy $(2,3)$. Initial recommendations were found to be numerous, country specific and was based on expert opinion rather than evidence based which limited its wide scale utilisation. Therefore, steps were taken to identify the significant quality measures and to shortlist the performance indicators that may be more practical and widely applicable $(2,3)$.

The American Society of Gastrointestinal Endoscopy/ American College of Gastroenterology (ASGE/ACG) and European Society of Gastrointestinal Endoscopy/United European Gastroenterology (ESGE/UEG) proposed their guidelines on key quality indicators which were derived from favourable clinical outcomes and enhanced quality of life. Furthermore, a practical and simple approach for quality measurement were analysed highlighting the area for improvement and were found to be widely adaptable (2, 3). In this review, we summarise the key quality or performance indicators proposed by these guidelines and discuss its relevance and usefulness. The rising incidence of CRC and inflammatory bowel disease in the region has become a significant burden and requires colonoscopies to be performed with adequate standards in terms of diagnostic yield and patient safety (4-6).

Quality indicators were categorised into pre-procedure, intraprocedure, and post-procedure and key performance measures were described (Table 1). 
Table 1. Summary of recommendations of quality in Colonoscopy

\begin{tabular}{|c|c|c|c|c|c|c|c|}
\hline & \multirow{2}{*}{ Quality indicator } & \multirow{2}{*}{$\begin{array}{l}\text { Measure } \\
\text { type }\end{array}$} & \multicolumn{2}{|c|}{ ASGE/ACG } & \multicolumn{3}{|c|}{ ESGE/UEG } \\
\hline & & & Evidence & $\begin{array}{c}\text { Target } \\
(\%)\end{array}$ & Evidence & $\begin{array}{c}\text { Target } \\
(\%)\end{array}$ & $\begin{array}{l}\text { Consensus } \\
\text { agreement }\end{array}$ \\
\hline \multicolumn{8}{|c|}{ Pre-procedure } \\
\hline 1 & $\begin{array}{l}\text { Proportion of colonoscopies with proper } \\
\text { indication and documentation of indication }\end{array}$ & Process & $1 \mathrm{C}+$ & $>80$ & Moderate & $=85 \%$ & $93.80 \%$ \\
\hline 2 & $\begin{array}{l}\text { Proportion of colonoscopies performed } \\
\text { following fully documented informed } \\
\text { consent }\end{array}$ & Process & $1 C$ & $>98$ & ND & ND & ND \\
\hline 3 & $\begin{array}{l}\text { Minimum time slot for colonoscopy } \\
\text { (minutes) }\end{array}$ & Structure & ND & ND & No evidence & $30-45$ & $100 \%$ \\
\hline 4 & $\begin{array}{l}\text { Proportion of colonoscopies that follow } \\
\text { recommended surveillance protocols for } \\
\text { post-polypectomy, post cancer-resection } \\
\text { and screening }\end{array}$ & Process & $1 \mathrm{~A}$ & $=90$ & ND & ND & ND \\
\hline 5 & $\begin{array}{l}\text { Proportion of colonoscopies that follow } \\
\text { recommended surveillance protocols for } \\
\text { inflammatory bowel disease }\end{array}$ & Process & $2 \mathrm{C}$ & $=90$ & ND & ND & ND \\
\hline \multicolumn{8}{|c|}{ Intra-procedure } \\
\hline \multirow[t]{2}{*}{6} & $\begin{array}{l}\text { Proportion of colonoscopies that properly } \\
\text { document quality of preparation }\end{array}$ & Process & 3 & $>98$ & ND & ND & ND \\
\hline & Proportion of adequate bowel preparation & Process & 3 & $=85$ & Moderate & $=90 \%$ & $100 \%$ \\
\hline \multirow[t]{3}{*}{7} & $\begin{array}{l}\text { Proportion of visualization of the caecum } \\
\text { with photo-documentation }\end{array}$ & \multirow[t]{3}{*}{ Process } & \multirow[t]{3}{*}{$1 C$} & & & & \\
\hline & $\begin{array}{l}\text { a) Caecal intubation rate with } \\
\text { photography (all examinations) }\end{array}$ & & & $=90$ & Moderate & $=90$ & $97.90 \%$ \\
\hline & $\begin{array}{l}\text { b) Caecal intubation rate with } \\
\text { photography (screening) }\end{array}$ & & & $=95$ & ND & ND & ND \\
\hline \multirow[t]{3}{*}{8} & $\begin{array}{l}\text { Proportion of adenoma detection in } \\
\text { asymptomatic average-risk individuals }\end{array}$ & \multirow[t]{3}{*}{ Outcome } & \multirow[t]{3}{*}{$1 \mathrm{C}$} & $=25$ & $\begin{array}{l}\text { Moderate to } \\
\text { high }\end{array}$ & $=25$ & $100 \%$ \\
\hline & Adenoma detection rate for male patients & & & $=30$ & ND & ND & ND \\
\hline & Adenoma detection rate for female patients & & & $=20$ & ND & ND & ND \\
\hline 9 & $\begin{array}{l}\text { Proportion of polyp detection in patients = } \\
50 \text { years }\end{array}$ & Outcome & ND & ND & Low & $40 \%$ & $84.60 \%$ \\
\hline \multirow[t]{2}{*}{$\begin{array}{l}1 \\
0\end{array}$} & $\begin{array}{l}\text { Proportion of measurement of withdrawal } \\
\text { time }\end{array}$ & Process & $2 \mathrm{C}$ & $>98$ & ND & ND & ND \\
\hline & $\begin{array}{l}\text { Average withdrawal time in negative-result } \\
\text { screening colonoscopies (minutes) }\end{array}$ & Process & $2 \mathrm{C}$ & $=6$ & Moderate & $=6 \mathrm{~min}$ & $87.50 \%$ \\
\hline \multirow[t]{2}{*}{$\begin{array}{l}1 \\
1\end{array}$} & $\begin{array}{l}\text { Proportion of obtaining biopsy specimens } \\
\text { when colonoscopy is performed for an } \\
\text { indication of chronic diarrhoea }\end{array}$ & Process & $2 \mathrm{C}$ & $>98$ & ND & ND & ND \\
\hline & $\begin{array}{l}\text { Proportion of obtaining recommended } \\
\text { tissue sampling for surveillance in ulcerative } \\
\text { colitis and Crohn's colitis }\end{array}$ & Process & $1 \mathrm{C}$ & $>98$ & ND & ND & ND \\
\hline \multirow[t]{2}{*}{$\begin{array}{l}1 \\
2\end{array}$} & $\begin{array}{l}\text { Proportion of endoscopic removal of } \\
\text { pedunculated polyps and sessile polyps }<2 \\
\mathrm{~cm} \text { is attempted before surgical referral }\end{array}$ & Outcome & 3 & $>98$ & ND & ND & ND \\
\hline & Appropriate polypectomy technique & Process & ND & ND & Low & $=80 \%$ & $93.30 \%$ \\
\hline $\begin{array}{l}1 \\
3 \\
\end{array}$ & $\begin{array}{l}\text { Proportion of non-diminutive polyp ( }>5 \mathrm{~mm} \\
\text { in size) retrieval }\end{array}$ & Process & ND & ND & Very low & $=90 \%$ & $86.70 \%$ \\
\hline $\begin{array}{l}1 \\
4\end{array}$ & Rectal examination and rectal retroflexion & Process & ND & ND & ND & ND & ND \\
\hline $\begin{array}{l}1 \\
5\end{array}$ & Advanced imaging assessment & Process & ND & ND & No evidence & $\begin{array}{l}\text { Unkno } \\
\text { wn }\end{array}$ & $93.30 \%$ \\
\hline $\begin{array}{l}1 \\
6 \\
\end{array}$ & Adequate description of polyp morphology & Process & ND & ND & Very low & $\begin{array}{c}\text { Unkno } \\
\text { wn }\end{array}$ & $84.60 \%$ \\
\hline
\end{tabular}

* ASGE/ACG: The American Society of Gastrointestinal Endoscopy/ American College of Gastroenterology; ESGE/UEG: European Society of Gastrointestinal Endoscopy/United European Gastroenterology; ND: Not defined

The Sri Lanka Journal of Surgery 2019; 37(4): 24-31 


\section{Pre-procedure quality indicators}

The quality measures in the pre-procedure period consist of those implemented before administrating the sedative medication and inserting the colonoscope (2).

\section{Appropriate indication for colonoscopy}

It is mandatory to document the indication clearly and when it is a nonstandard indication, the justification for doing colonoscopy should be documented. Furthermore, it is encouraged to review and document previous colonoscopies with date, findings, interventions and histology.

\section{Informed written consent}

Consent should be obtained from the patient or guardian for each colonoscopy while discussing the benefits, adverse events and other alternatives to endoscopy (2). The common adverse events such as perforation, bleeding, infection, missed lesions and adverse events related to sedation, bowel preparation and intravenous access should be disclosed and explained to the patient.

\section{Time slot allocated for colonoscopy}

A minimum of 30 minutes should be taken for a routine colonoscopy while at least 45 minutes should be taken for colonoscopies for faecal occult blood testing to permit therapeutic interventions (3). Proper assessment of the colon requires adequate time and there is evidence to show that productivity pressure may negatively influence the quality of the procedure (3).

4.Appropriate surveillance protocols following postpolypectomy, post-cancer resection and negative screening colonoscopies.

The rationale is to maintain a high yield while ensuring costeffectiveness and minimising harm by optimising the interval between colonoscopies. These recommended intervals assume that effective complete examination of the large bowel with good bowel preparation was carried out while clearing all neoplasia and precancerous lesions.

Brenner et al have shown that negative screening colonoscopy was related to protection against CRC for 20 years (7). Furthermore, a repeat colonoscopy after 5 years following a negative screening colonoscopy resulted in very low yield. Thus a consensus of 10 years interval following a routine negative screening colonoscopy was reached. Lack of awareness about the guidelines has resulted in more frequent colonoscopies leading to negative studies with increased risk and cost (2). Guidelines for intervals between examinations following the detection of a pre-cancerous lesion depends on the successful clearance during colonoscopy, size, number and the histology type of the precancerous lesion (8). The British guidelines classify the baseline colonoscopy into three categories: High-risk category (more than five small adenomas or three adenomas-one $>10 \mathrm{~mm}$ ), Intermediate risk category (three to four small adenomas or one $>10 \mathrm{~mm}$ ) and low-risk category (less than three small adenomas $<10 \mathrm{~mm}$ ). The next surveillance colonoscopy should be discussed with the patient and scheduled for high risk at one year, intermediate-risk at three years and low risk, no surveillance or at 5 yearly intervals (9). Evidence for certain precancerous lesions such as serrated adenomas is limited (8).

\section{Appropriate surveillance protocols for inflammatory bowel disease}

Long term ulcerative colitis and Crohn's disease (CD) are associated with increased risk of cancer $(5,6)$. Patients with colitis should be subjected to endoscopic surveillance starting from 8 years after initial manifestation (not after initial diagnosis). Risk factors which determine the frequency of surveillance are primary sclerosing cholangitis, first degree relative with $\mathrm{CRC}$, strictures, previous dysplasia not undergone resection, post inflammatory polyps and extent of inflammation.

Patients with isolated ulcerative proctitis and $\mathrm{CD}$ without colonic inflammation are not at increased risk to develop CRC and should not have screening colonoscopies. According to the risk factors, the European Crohn's and Colitis Organisation guideline stratifies the risk to develop CRC as high-risk (needs colonoscopy annually), intermediate-risk (needs colonoscopy every 2-3 yearly) and low-risk (needs colonoscopy every 5 yearly) (10).

\section{Intra-procedure quality measures}

Good quality assessment of the large bowel includes complete intubation of the colon and a thorough mucosal examination. The intra-procedure component begins at the administration of sedative agents, or insertion of the scope in cases without sedation, to complete withdrawal of the endoscope and includes diagnostic and therapeutic manoeuvres (2).

\section{Quality of bowel preparation}

The quality of colonoscopy is largely determined by the quality of bowel preparation. Bowel preparation is related to caecal intubation and adenoma detection rates (ADR) which are important quality measures in colonoscopy (3).

Terms such as good, fair and poor or scoring systems may be used. However, there are shortcomings in using each of the above (2). Several validated scales are available such as the Ottawa Scale, Boston Bowel Preparation Scale (BBPS) and the Aronchick Scale. BBPS is recommended by the ESGE guidelines as the preferred scale (3). Irrespective of the scoring method, quality of bowel preparation should be 
documented depending on the ability to detect polyps, at least $>5 \mathrm{~mm}$ in size following adequate suctioning of retained fluid or faeces. If bowel preparation is inadequate, a repeat colonoscopy should be performed within 1 year (8). Poor bowel cleansing reduces the effectiveness of colonoscopy in the detection of lesions, performing therapeutic procedures and prolongs examination and withdrawal time (2).

Patients' understanding and compliance are essential in bowel preparation and successful colonoscopy. A systematic review of 56 studies analysed the patients' perception and barriers in bowel preparation and colonoscopy. Factors such as lack of awareness, anxiety, the anticipation of pain, embarrassment and vulnerability were patient reported barriers in bowel preparation and colonoscopy. Therefore, these should be addressed to improve quality of preparation (11).

Furthermore, patients' perception of the quality of their bowel preparation was found to be unreliable and therefore, the bowel cleansing regime should be strictly completed to achieve adequate preparation (12). According to Hillyer et al, a patient's inability to tolerate the full course of purgative was considered the most common barrier to optimal bowel preparation (13). To improve the patients' tolerance and compliance, the ASGE recommends split-dosing of bowel preparations for all patients, i.e. half the bowel preparation is administered on the day of the procedure, allowing a snack on the night before the procedure during the time the patient would be otherwise advised to be fasting for solids (2). If the proportion of inadequate bowel preparation is greater than $15 \%$, protocols should be re-examined in terms of patient education, agent used and the protocol of administration (2).

\section{Caecal intubation (CI) and photo-documentation of landmarks}

Visualization of the cecum by identification of landmarks and photo-documentation should be achieved in at least $90 \%$ and $95 \%$ in all examinations and screening colonoscopies respectively (2).

$\mathrm{CI}$ is the passage of the tip of the colonoscope just proximal to the ileocaecal valve, completely visualising the caecal caput and the part between the appendiceal orifice and ileocaecal valve. Low CI rates are related to increased rates of interval proximal large bowel malignancies as a substantial proportion of cancer originate from the right colon (14). Failed CI results in further costs and inconvenience due to rescheduling examination or arranging alternative investigations (14). CI should ideally be photo-documented by naming the identified caecal landmarks, specifically the ileocaecal valve and appendiceal orifice.

Colonoscopies aborted due to inadequate bowel preparation or severe colitis and subsequent procedures following a recent full colonoscopy done for therapeutic purposes need not be included in determining CI rates.

\section{Adenoma detection rate (ADR)}

The rate of adenoma detection in asymptomatic, average-risk individuals for screening should be greater than $25 \%$ of the population (for males $>30 \%$ and females $>20 \%)(2,3)$.

A large scale study (15) presented the ADR in 223,842 patients who underwent 264,792 colonoscopy procedures by 136 gastroenterologists, with a follow up of 10 years. The ADRs ranged from $7.4 \%$ to $52.5 \%$ and were sorted into quintiles during the analysis. The unadjusted risks for interval $\mathrm{CRC}$ in the $\mathrm{ADR}$ quintiles from highest to lowest were found to be increasing substantially $(4.8,7.0,8.0,8.6$, and 9.8 cases per 10,000 person-years of follow-up) (15). A 3\% decrease in the incidence of $\mathrm{CRC}$ with a $5 \%$ decrease in the cancer-related mortality was shown for each $1 \%$ rise in ADR highlighting its significance (15). Based on this new evidence, minimum targets for ADR was formulated. Thus, all colonoscopists should measure their ADRs, and those with overall ADRs less than $25 \%$ must take measures for improvement. However, minimum targets for ADR for the South Asian population where there is a lower incidence of $\mathrm{CRC}$ and adenomatous polyps, have not been determined. Nevertheless, the above targets may be utilised as performance indicators without considering these as the standard of care.

ADR is now considered the single most useful quality assessment in colonoscopy. Colonoscopists with higher ADRs clear colons of precancerous lesions better and follow up patients at shorter intervals. This is because the recommended intervals for repeat assessment are smaller in precancerous lesions. Those with low ADRs detect lesser patients with precancerous lesions and multiple lesions, putting patients at greater risk for CRC. This is by failing to clear the large bowel from precancerous lesions and assigning inappropriately longer intervals for a repeat colonoscopy. Therefore, knowing the personal ADR is important to ensure optimal patient protection (16).

However, there are several concerns regarding ADR as the best overall quality measure. ADR requires documentation of histology data which needs extra effort from the endoscopy unit. Secondly, it will reward a "one and done" approach i.e. after identifying one polyp endoscopically compatible with an adenoma, there may be a natural tendency to refrain from assessing the remaining colonic mucosa as meticulously.

Several other alternatives to ADR such as polyp detection rate (PDR) which has the advantage of not requiring pathological data have been considered. However, there is a lack of 
evidence to support PDR as an alternative quality indicator for ADR (17). Adenoma per colonoscopy (APC) rate is another alternative to ADR which is now being used commonly used in clinical trials (18). APC overcomes the problem of "one and done". However, may lead to increased pathological costs if each polyp is sent separately for pathological analysis. Use of photography to document the identification of multiple adenomas may help to overcome this problem. Several simple interventions such as education, feedback, and standardising the quality of colonoscopy have shown to increase ADR (3).

\section{Polyp detection rate (PDR)}

PDR is easier to measure than ADR as histological verification is not required. A recent study showed that PDR was non-inferior to ADR in terms of CRC risk prediction (19). However, in general, there is still a lack of evidence to support PDR as an alternative to ADR. ESGE guidelines proposed a minimum standard of $40 \%$ for PDR (3). PDR may be used instead of ADR if there is limited availability of histology. However, there is a potential risk of "gaming" where pressure on quality may result in the removal of non-neoplastic lesions ("so-called polyps") that would otherwise go unidentified inorder to falsely increase the PDR (3).

\section{Withdrawal time}

The minimum withdrawal time for a negative screening procedure is 6 minutes $(2,3)$.

Careful inspection of the colon takes times. Increased identification of significant neoplastic lesions is noted when the mean withdrawal time is 6 minutes. Nevertheless, withdrawal time is only secondary to ADR in measuring quality. Therefore, in those with high ADR withdrawal time may not be essential. However, withdrawal time may help as a supportive tool to help correct the performance of those with substandard ADR (20). Furthermore, variation in withdrawal technique is more essential than the withdrawal time which is difficult to assess (3).

\section{Tissue sampling}

Patient's chronic diarrhoea due to microscopic colitis (lymphocytic and collagenous colitis) may have macroscopically normal mucosa. Thus requiring multiple biopsies of otherwise unremarkable appearing colon (2).

In inflammatory bowel disease, a recent randomized study showed that pancolonic chromoendoscopy and targeted biopsies gave a better yield of dysplasia with fewer biopsies (21). However, a systematic biopsy protocol can be utilised as an alternative (22).

\section{Endoscopic polypectomies}

The majority of sessile polyps less than $2 \mathrm{~cm}$ in size are readily removable endoscopically, depending on their shape, size, location and accessibility (23). Endoscopic resection is more economically feasible and safer than surgery (23). Difficult polypectomies should be referred to experienced endoscopists before surgical referral. In that case, snare resection of even a part of the polyp should be avoided as it may create a false-positive non-lifting sign, making subsequent attempts at endoscopic resection increasingly difficult. In doubtful cases, a second opinion by more experienced endoscopists after review of photographs can confirm the need for a surgical referral. Furthermore, it is recommended that lesions which are located in areas that cannot be identified with certainty by endoscopy, should be marked with carbon black in 3 to 4 quadrants before sending for surgical resection to ensure proper resection (2).

According to ESGE guidelines, proper resection methods of small and diminutive colonic polyps include removal of polyps $\leq 3 \mathrm{~mm}$ by biopsy forceps and snare polypectomy for larger polyps.

\section{Polypectomy retrieval rate}

The proportion of non-diminutive polyp ( $>5 \mathrm{~mm}$ in size) retrieval should be more than $90 \%$ (3). This is because retrieval of polyps is essential for histopathology which guides further management. Diminutive polyps which are $\leq 5$ $\mathrm{mm}$ in size are associated with a lower risk for CRC (24). Therefore monitoring retrieval rates of polyps more than 5 $\mathrm{mm}$ in size are clinically more important. The process of removing larger polyps is technically more difficult (3).

\section{Rectal examination and rectal retroflexion}

Recording of rectal examination or omission must be achieved in $100 \%$ of cases. Furthermore, rectal retroflexion must be done in $90 \%$ of cases (25).

Digital rectal examination (DRE) should be performed in a standard endoscopic assessment of the lower gastrointestinal tract to examine the anal canal and lower rectum and also to facilitate the insertion of the endoscope through the anal canal. Several studies have shown an increased rate of detection (up to $8 \%$ ) of pathology by retroflexion after standard visualisation of the rectum (26).

\section{Advanced imaging assessment}

The NICE (NBI International Colorectal Endoscopic) Classification is a useful guideline for narrow-band images of colon polyps. The classification uses colour, surface patterns and vascular patterns to distinguish between hyperplastic, adenomatous and malignant polyps (27). 
- Type 1 or hyperplastic polyps are characterised by the same or lighter colour compared with the background with white or dark spots of similar size or homogenous absence of surface pattern. Blood vessels may be absent or isolated lacy blood vessels may be seen over the lesion.

- Type 2 or adenomatous polyps are characterized by the brown tinge compared to the background with tubular, oval or branched white surface structures with surrounding brown vessels.

- Type 3 or malignant polyps appear brown to dark brown compared to the background with occasional whiter patchy areas and amorphous or absent surface pattern. They consist of disrupted or missing vessels (27).

The ESGE guidelines described the use of advanced endoscopic imaging for identification and differentiation of neoplasia of the colon in terms of assessment of margin, depth and invasion. (24).

\section{Adequacy in the description of polyp morphology}

The ESGE guidelines proposed that Paris classification which was developed to standardise the terminology for the morphology of superficial colorectal lesions should be routinely used for describing lesions at colonoscopy $(3,28)$. However, the minimum standard is not established.

\section{Tattooing resection sites}

In patients undergoing excision of colorectal lesions with a depressed area (0-IIc) or non-granular or mixed-type laterally spreading tumours, located in areas which cannot be accurately specified during colonoscopy, i.e. from ascending to the sigmoid colon, the part to be resected should undergo tattooing to aid in future identification (3).

Colorectal lesions with a higher risk of cancer often need relocation to detect recurrence and to aid in further treatment. Tattooing is proven to significantly reduce the time taken to re-locate the resection site on colonoscopy (29).

\section{Post-procedure quality indicators}

The post-procedure period spans from the time of removal of the endoscope to further management and follow-up.

\section{Incidence of perforation and bleeding after polypectomy} Incidence of bowel perforation should be $<1: 500$ and $<1: 1000$ in all examinations and screening colonoscopies respectively. Perforation is recognised as the most serious adverse event in colonoscopy and around 5\% have been reported to be fatal (30).

The commonest adverse event following polypectomy is bleeding. The overall frequency of bleeding following polypectomy should be $<1 \%(2,30)$. The risk of postpolypectomy bleeding rises with the size of the polyp, proximal colon polyps, anticoagulation and antiplatelets (2). The proportion of successful management of postpolypectomy bleeding without surgery should be more than $90 \%$. In cases of ongoing bleeding, endoscopic therapeutic measures such as re-grasping the stalk of the polyp and holding for 10-15 minutes, applying clips, epinephrine injections and cautery usually result in successful haemostasis. Immediate bleeding after polypectomy is not an adverse event as long as it does not result in transfusions, hospitalization or surgery.

\section{Priority indicators for quality in colonoscopy}

The three most important priority indicators are ADR, the use of recommended intervals for repeat colonoscopies and CI rate with photographic documentation. Reaching the recommended standard for each of these parameters is strongly related to clinical outcomes.

\section{Corrective measures for poor performance}

The objective in assessing the quality is to identify poor performers and take measures for improvement. When colonoscopists have suboptimal ADRs, steps should be taken to demonstrate improvement. Such measures include improvement of the withdrawal times, using split-dose bowel preparation, education about withdrawal techniques while visualising the proximal sides of mucosal folds, clearing up excess fluid, mucus and faeces while ensuring sufficient colon distension (31).

\section{Conclusion}

This review summarises the current expert consensus on performance indicators related to quality in colonoscopy. Adhering to quality measures will help to improve yield while minimising patient harm and make the process cost-effective. Therefore, performing good-quality colonoscopy with proper documentation has become the most essential role of the endoscopist to reduce the incidence and mortality of CRC.

All authors disclose no conflict of interest. The study was conducted in accordance with the ethical standards of the relevant institutional or national ethics committee and the Helsinki Declaration of 1975, as revised in 2000 .

\section{References}

1. Ball J E, Osbourne J, Jowett S, Pellen M, Welfare M R. Quality improvement programme to achieve acceptable colonoscopy completion rates: prospective before and after study. BMJ: British Medical Journal 2004; 329: 665. https://doi.org/10.1136/bmj.329.7467.665

2. Rex D K, Schoenfeld P S, Cohen J et al. Quality indicators for colonoscopy. The American journal of gastroenterology 2015; 110. https://doi.org/10.1038/ajg.2014.385 
3. Kaminski MF, Thomas Gibson S, Bugajski Met al.

Performance measures for lower gastrointestinal endoscopy: a European Society of Gastrointestinal Endoscopy (ESGE) quality improvement initiative. United European gastroenterology journal 2017; 5: 309-34.

https://doi.org/10.1177/2050640617700014

4. Cancer Incidence Data, National Cancer Control Programme Sri Lanka (cited 2018 14.1.2018); Available from: http://www.nccp.health.gov.lk/index.php/publications/cancerregistries

5. Jayarajah U, Navarathne NMM, Samarasekera N, Subramaniam N, de Zoysa IM, Seneviratne SL. Epidemiology, Pathogenesis and Treatment of Ulcerative Colitis in South Asia. International Journal of Progressive Sciences and Technologies 2017; 6: 8.

6. Jayarajah U, Navarathne NM, de Zoysa IM, Subramaniam N, Samarasekera N, L Seneviratne S. Crohn's Disease in South Asia. International Journal of Progressive Sciences and Technologies 2017; 6: 12 .

7. Brenner H, Chang-Claude J, Seiler CM, Hoffmeister M. Longterm risk of colorectal cancer after negative colonoscopy. J. Clin. Oncol. 2011; 29: 3761-7.

https://doi.org/10.1200/JCO.2011.35.9307

8. Lieberman DA, Rex DK, Winawer SJ, Giardiello FM, Johnson DA, Levin TR. Guidelines for colonoscopy surveillance after screening and polypectomy: a consensus update by the US Multi-Society Task Force on Colorectal Cancer.

Gastroenterology 2012; 143: 844-57.

https://doi.org/10.1053/j.gastro.2012.06.001

9. Atkin W, Saunders B. Surveillance guidelines after removal of colorectal adenomatous polyps. Gut 2002; 51:v6-v9.

https://doi.org/10.1136/gut.51.suppl_5.v6

10. Annese V, Beaugerie L, Egan L et al. European evidence-based consensus: inflammatory bowel disease and malignancies. Journal of Crohn's and Colitis 2015; 9: 945-65.

https://doi.org/10.1093/ecco-jcc/jjv141

11. McLachlan SA, Clements A, Austoker J. Patients' experiences and reported barriers to colonoscopy in the screening context--a systematic review of the literature. Patient education and counseling 2012; 86: 137-46.

https://doi.org/10.1016/j.pec.2011.04.010

12. Harewood GC, Wright CA, Baron TH. Assessment of patients' perceptions of bowel preparation quality at colonoscopy. The American journal of gastroenterology 2004; 99: 839-43. https://doi.org/10.1111/j.1572-0241.2004.04176.x

13. Hillyer GC, Basch CH, Basch CE et al. Gastroenterologists' perceived barriers to optimal pre-colonoscopy bowel preparation: results of a national survey. J Cancer Educ 2012; 27: 526-32. https://doi.org/10.1007/s13187-012-0364-x

14.Baxter NN, Sutradhar R, Forbes SS, Paszat LF, Saskin R, Rabeneck L. Analysis of administrative data finds endoscopist quality measures associated with postcolonoscopy colorectal cancer. Gastroenterology 2011; 140: 65-72.

https://doi.org/10.1053/j.gastro.2010.09.006

15.Corley DA, Jensen CD, Marks AR et al. Adenoma detection rate and risk of colorectal cancer and death. N. Engl. J. Med. 2014; 370: 1298-306. https://doi.org/10.1056/NEJMoa1309086
16.Hewett DG, Rex DK. Improving colonoscopy quality through health-care payment reform. The American journal of gastroenterology 2010; 105: 1925.

https://doi.org/10.1038/ajg.2010.247

17.Williams JE, Le TD, Faigel DO. Polypectomy rate as a quality measure for colonoscopy. Gastrointest. Endosc. 2011; 73: 498506. https://doi.org/10.1016/j.gie.2010.08.008

18.Kahi CJ, Anderson JC, Waxman I et al. High-definition chromocolonoscopy vs. high-definition white light colonoscopy for average-risk colorectal cancer screening. The American journal of gastroenterology 2010; 105: 1301. https://doi.org/10.1038/ajg.2010.51

19.Kaminski MF, Wieszczy P, Kolacz A et al. Tu1006 Comparison of Quality Measures for Detection of Neoplasia at Screening Colonoscopy. Gastrointest. Endosc. 2016; 83: Ab527.

https://doi.org/10.1016/j.gie.2016.03.1067

20.Barclay RL, Vicari JJ, Greenlaw RL. Effect of a time-dependent colonoscopic withdrawal protocol on adenoma detection during screening colonoscopy. Clin. Gastroenterol. Hepatol. 2008; 6: 1091-8.

https://doi.org/10.1016/j.cgh.2008.04.018

21.Wu L, Li P, Wu J, Cao Y, Gao F. The diagnostic accuracy of chromoendoscopy for dysplasia in ulcerative colitis: metaanalysis of six randomized controlled trials. Colorectal Dis. 2012; 14: 416-20.

https://doi.org/10.1111/j.1463-1318.2010.02505.x

22.Rutter M, Saunders B, Wilkinson K et al. Cancer surveillance in longstanding ulcerative colitis: endoscopic appearances help predict cancer risk. Gut 2004; 53: 1813-6.

https://doi.org/10.1136/gut.2003.038505

23.Moss A, Bourke MJ, Williams SJ et al. Endoscopic mucosal resection outcomes and prediction of submucosal cancer from advanced colonic mucosal neoplasia. Gastroenterology 2011; 140: 1909-18.

https://doi.org/10.1053/j.gastro.2011.02.062

24.Kamiński MF, Hassan C, Bisschops R et al. Advanced imaging for detection and differentiation of colorectal neoplasia: European Society of Gastrointestinal Endoscopy (ESGE) Guideline. Endoscopy 2014; 46: 435-57.

https://doi.org/10.1055/s-0034-1365348

25.Conway R, Low C, Coughlan RJ, O'Donnell MJ, Carey JJ. Methotrexate use and risk of lung disease in psoriasis, psoriatic arthritis, and inflammatory bowel disease: systematic literature review and meta-analysis of randomised controlled trials. Bmj 2015; 350: h1269. https://doi.org/10.1136/bmj.h1269

26.El Younis C. Correlation of preprocedure digital rectal examination and rectal retroflexion during colonoscopy of asymptomatic patients. Gastroenterologia y hepatologia 2009; 5: 201-4. https://doi.org/10.1016/j.gie.2009.03.500

27. Patrun J, Okreša L, Iveković H, Rustemović N. Diagnostic Accuracy of NICE Classification System for Optical Recognition of Predictive Morphology of Colorectal Polyps. Gastroenterology research and practice 2018; 2018. https://doi.org/10.1155/2018/7531368

28. ei Kudo S, Lambert R, Allen JI et al. Nonpolypoid neoplastic lesions of the colorectal mucosa. Gastrointest. Endosc. 2008; 68: S3-S47. https://doi.org/10.1016/j.gie.2008.07.052 
29.Wang R, Wang Y, Li D et al. Application of carbon nanoparticles to mark locations for re-inspection after colonic polypectomy. Surg. Endosc. 2016; 30: 1530-3.

https://doi.org/10.1007/s00464-015-4367-7

30. Nivatvongs S. Complications in colonoscopic polypectomy. Dis. Colon Rectum 1986; 29: 825-30.

https://doi.org/10.1007/BF02555356
31. Lee RH, Tang RS, Muthusamy VR et al. Quality of colonoscopy withdrawal technique and variability in adenoma detection rates (with videos). Gastrointest. Endosc. 2011; 74: 128-34 https://doi.org/10.1016/j.gie.2011.03.003 